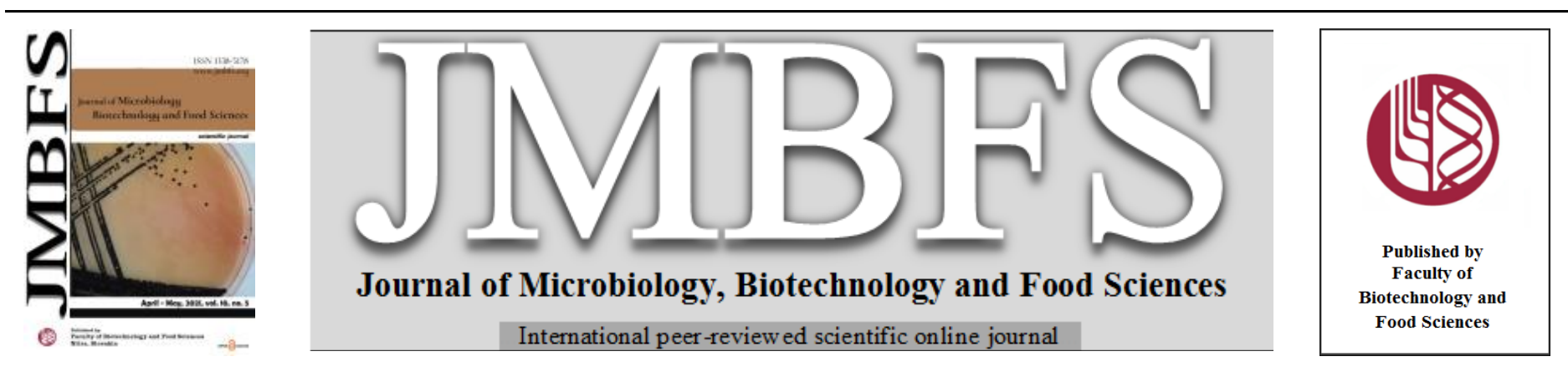

\title{
EFFECT OF DIETARY RED GRAPE POMACE ON LIPID OXIDATION IN MEAT OF BROILER CHICKENS
}

\author{
Lukáš Jurčaga $*^{l}$, Marek Bobko ${ }^{1}$, Peter Haščík ${ }^{l}$, Alica Bobková ${ }^{2}$ Alžbeta Demianová ${ }^{2}$, Lubomír Belej ${ }^{2}$, Miroslav Kročko $^{l}$
}

\author{
Address(es): \\ ${ }^{1}$ Slovak University of Agriculture in Nitra, Faculty of Biotechnology and Food Sciences, Department of Technology and Quality of Animal Products , Tr. A. Hlinku 2, \\ 94976 Nitra, Slovakia. \\ ${ }^{2}$ Slovak University of Agriculture in Nitra, Faculty of Biotechnology and Food Sciences, Department of Food Hygiene and Safety, Tr. A. Hlinku 2, 94976 Nitra, \\ Slovakia.
}

*Corresponding author: xjurcaga@uniag.sk

https://doi.org/10.15414/jmbfs.3769

\section{ARTICLE INFO}

Received 29. 9. 2020

Revised 24. 11. 2020

Accepted 3. 12. 2020

Published 1. 4. 2021

Regular article

OPEN $\partial_{\text {ACCESS }}$

\begin{abstract}
Grape pomace is a by-product of grape processing and represents a major waste issue. One of the possible methods of revalorization of this agriculture waste is to incorporate red grape pomace into the feed mixture of poultry e.g. broiler chickens. The rich content of polyphenols in red grape pomace is reported to have a positive protective effect against lipid oxidation in several types of meat and products. In our study, we incorporate red grape pomace into the diet of observed Ross 308 broiler chickens. Tested chickens were divided into 4 groups. One control group without any addition of pomace, and another three groups with the addition of 1,2, and $3 \%$. After 42 days chickens were slaughtered and tested. To evaluate the process of lipid oxidation we used measurement of malonaldehyde (MDA) presented in samples of breast and thigh meat. MDA measurement was carried out on the 1st, 3rd, and 5th day of meat storage at $4{ }^{\circ} \mathrm{C}$. However, our study did not prove any significant difference among the control group without red grape pomace and the other three experimental groups. We can see a slight decrease in MDA created during the storage process but not with statistically provable results. The repetition of the experiment with some adjustment is highly anticipated.
\end{abstract}

\section{INTRODUCTION}

Wine grapes (Vitis vinifera) are one of the most cultivated fruits in the world with an approximate yearly production of 77 million metric tons. After processing grapes for standard products such as wine or juice, by-products like skins and seeds are left in form of pomace. Grape pomace represents about $20 \%$ of fruit weight. Due to this large volume of produced residues economic and ecological problems occur. It is anticipated that any useful application of these by-products would keep the environmental balance and economic evaluation of the raw material could be considered (Ebrahimzadeh et al., 2018).

Their revalorization, in a form of nutritious additive in chicken feed, could provide an environmentally tenable as well as a budget option to current methods of disposal. This improvement of feed can possibly increase nutrition security, furthermore, being beneficial for the health of consumers of poultry meat and products. Grape pomace is indeed a rich source of phenolics with significant antimicrobial and antioxidants properties, as well as pigments that may have a positive impact on the color and shelf stability of poultry meat (Aditya $\boldsymbol{e t}$ al., 2018).

Authors Xia et al. (2010) reviewed the amount of certain phenolic compounds in different parts of grape. Grape skins are proven to be abundant sources of anthocyanins, hydroxycinnamic acids, flavanols, and flavonol glycosides. On the other hand, grape seeds contain mainly gallic acid and flavanols. McCalluma $\boldsymbol{e t}$ al. (2007) had separated thirty-seven anthocyanins from grape skin of Concord cultivar. Among identified grape pomace anthocyanins, five were 3-Omonoglucosides of delphinidin, cyaniding, petunidin, peonidin, and mavidin; another five of them are the acetylglucosides of the five anthocyandins. Predominant anthocyanin was found to be malvidin 3-O-glucoside. Grape seeds contain a considerable amount of monomeric phenolic compounds, such as $(+)-$ catechins, (-)-epicatechin and (-)-epicatechin-3-Ogallate, and dimeric, trimeric, and tetrameric procyanidins. The content anthocyanin can be significantly affected by the type of wine vinification and contact time, thus the content of anthocyanin may be lowered with longer contact time, the lower the anthocyanin content remains in the pomace (Gómez-Plaza et al., 2006). Grape skins and seeds are rich sources of flavonoids including monomeric phenolic compounds, such as (+)-catechins, (-)-epicatechin, and (-)-epicatechin-3-O-gallate and dimeric, trimeric, and tetrameric procyanidins. Studies have shown flavonoids have the ability of being efficient antioxidants given being able to neutralize free radicals and terminating oxidative reactions (González-Paramás et al., 2004). Polyphenols of grape pomace can be significantly useful in preventing a damage caused by an oxidation process in biological molecules. This could positively improve grow performance and meat quality of broiler chickens. Furthermore, as it was reported, grape pomace has an ability to increase levels of glutathione and catalase which enhance the immune function of an organism. Regarding meat stability, the addition of grape pomace into the chicken diet has been reported to delay lipid oxidation in meat, and therefore prolonging the shelf life of chicken meat and products (Chamorro et al., 2015).

Chicken meat and products are popular with customers all around the world. Chicken meat has many favorable nutritional characteristics such as low lipid contents and a relatively high concentration of polyunsaturated fatty acids. Also, fatty acids profile could be further enhanced by strategies targeted to the diet of reared animals (Bourre, 2005). However, relatively high content of polyunsaturated fatty acids makes chicken meat considerably susceptible to a deterioration caused by oxidation processes. A dietary manipulation, represented by the increasing the unsaturation degree of the membranes in muscle, increases the susceptibility of chicken meat to the damage caused by the oxidation, which can take place during storage, but as a consequence, nutritional value or flavor may decrease (Enberg et al., 1996). Mostly the addition of $\alpha$-tocopheryl acetate, which was added to the diet of observed poultry specie, was responsible for the oxidative stability of the meat. The oxidative stability of poultry meat depends mostly on the. This, however, presents several drawbacks which mainly include its synthetic origins and low bio efficiency (Allard et al., 1997).

Reports, previously stated by Goñi et al. (2007), Brenes et al. (2008), suggest that the increase of antioxidant capacity in breast and tight meat of broiler chickens can be caused by the intake of grape pomace. Those increases were very similar to groups with added vitamin $\mathrm{E}$ in their diets. Furthermore, it was observed that grape seeds extract, and other plant extracts had an antioxidative effect on chicken meat in the work of Mitsumoto et al. (2005). 


\section{MATERIAL AND METHODS}

\section{Animals and diet}

Our experiment is subsequent work on experiment of authors Haščík et al (2020), therefore we used same feeding mixture as original authors. Experiment was carried out using broiler chickens, hybrid Ross 308 of random mixed sex. Four observation groups were created, each group consisting of 50 animals Control group, without any grape pomace addition. Experimental chicken groups were fed a complete feed mixture with various grape pomace content. E1 group ( $1 \%$ addition), E2 group (2\% addition) and E3 group (3\% addition). Broilers were subjected to a two-phase feeding program, starter HYD-01 (1 -21 d), and grower HYD-02 (22 - 42 d) diets. The compositions of basal diets are presented in Table 1. Both starter and grower mixture were prepared by Biofeed, Inc. (Kolárovo, Slovak Republic).

\section{Slaughter and fat measurement}

After forty-two days of age, 10 chicken were selected (5 $\hat{O}$ and 5 P) from each of the experimental groups, as well as from the control group. They were chosen based on their average weight and subsequently slaughtered at the experimental slaughterhouse of the Department of Technology and Quality of Animal Products (SUA, Nitra)

Fat measurement in samples was carried using INFRATEC 1265 device (Germany) (g.100 g

\section{Grape pomace}

For the purposes of the experiment grape pomace of Alibernet variety. Nutrient composition was the same as in primary experiment of authors Hašćík et al. (2020).

\section{MDA measurement}

Measurement of MDA was carried out on the 1st, 3rd, and 5th days of storage at $4{ }^{\circ} \mathrm{C}$.

For the purpose of analysis, we used $1.5 \mathrm{~g}$ of a tissue sample. To sample was added $1 \mathrm{ml}$ of EDTA, $5 \mathrm{ml}$ of $0.8 \%$ butylated hydroxytoluene solution (BHT) and mixed gently. Subsequently, we added $8 \mathrm{ml}$ of $5 \%$ trichloroacetic acid solution (TCA) and homogenized sample for 30 seconds at $10000 \mathrm{rpm}$ (IKA T 18 digital ULTRA-TURRAX®, Germany). Next, the sample was left to chill for 10 minutes and then centrifuged for 5 minutes at 3,500g at temperature $4{ }^{\circ} \mathrm{C}$ (Hettich
Universal 320, Germany). The top hexane layer was separated from the sample and discarded. The rest of the sample was filtrated (Whatman 4) into the $10 \mathrm{~m}$ volumetric bank and refill with the volume by $5 \%$ TCA solution. $4 \mathrm{ml}$ of the prepared sample was mixed with $1 \mathrm{ml}$ 2-thiobarbituric acid (TBA), incubated in a water bath with temperature $70{ }^{\circ} \mathrm{C}$ for 90 minutes and left to cool down to room temperature for 45 minutes. After that, the absorbance of the sample was measured using UV-spectrophotometry at a wavelength of $532 \mathrm{~nm}$ (Jenway 7305, UK). Final results were calculated using a calibration curve and expressed as the quantity of malondialdehyde (MDA) (mg) present in $1 \mathrm{~kg}$ of sample.

\section{Statistical analysis}

To compare individual groups, we used single factor ANOVA analysis. Level of significance for test was set to $\alpha=0,05$. To carry out statistical analysis program SAS (version 9.3, SAS Institute Inc., USA, 2008).

\section{RESULTS AND DISCUSSION}

The experiment of feeding broilers Ross 308 with red grape pomace (Alibernet variety) was aiming to evaluate oxidative stress in meat samples. This was expressed as the amount of malondialdehyde (MDA) measured in breast and thigh meat on the 1st, 3rd, and 5th day of storage. Subsequently, we compare our results with statistical analysis.

Lipid oxidation is the major challenge that processors of meat and poultry are facing. Oxidation of molecules is characterized by the loss of one or more electrons, generally through the removal of hydrogen atoms, and often results in the addition of molecular oxygen (Papuc et al., 2017). Products with high-fat content, such as processed meat products, are more susceptible to oxidative chain reactions, which can result in undesirable odors and flavors, as well as nutrients loss (Hygreeva et al., 2014)

Malondialdehyde (MDA) is a relatively stable secondary product of the oxidative degradation of polyunsaturated fatty acids (PUFAs). It is a three-carbon dialdehyde that can exist in various forms depending on the $\mathrm{pH}$ value (Lima et al., 2013). MDA is very important for industry and scientific research since it can be used for determination of lipids peroxidation through the TBARS test (Thiobarbituric Acid Reactive Substances), the most widely used assay to assess the effects of lipid oxidation on meat and meat products (Min \& Ahn, 2005 ).

Chicken meat generally contains a small amount of fat tissue. Nonetheless, that does not mean that chicken meat is not affected by changes caused by lipid oxidation. The presence of such processes is clearly visible by increasing the amount of malondialdehyde (MDA) during the observation period.

Table 1 MDA values in chicken breast meat

\begin{tabular}{|c|c|c|c|c|c|c|c|}
\hline Parameter & Day & Sex & C & E1 & E2 & E3 & p-value \\
\hline \multirow{6}{*}{ MDA } & \multirow{2}{*}{ Day 1} & Male & $0.042 \pm 0.013$ & $0.055 \pm 0.009$ & $0.050 \pm 0.013$ & $0.044 \pm 0.024$ & 0.842 \\
\hline & & Female & $0.061 \pm 0.013$ & $0.075 \pm 0.044$ & $0.040 \pm 0.025$ & $0.045 \pm 0.023$ & 0.628 \\
\hline & \multirow{2}{*}{ Day 3} & Male & $0.183 \pm 0.013$ & $0.199 \pm 0.010$ & $0.180 \pm 0.036$ & $0.188 \pm 0.035$ & 0.890 \\
\hline & & Female & $0.186 \pm 0.014$ & $0.179 \pm 0.008$ & $0.172 \pm 0.018$ & $0.173 \pm 0.011$ & 0.724 \\
\hline & \multirow{2}{*}{ Day 5} & Male & $0.210 \pm 0.007$ & $0.209 \pm 0.008$ & $0.204 \pm 0.010$ & $0.208 \pm 0.014$ & 0.944 \\
\hline & & Female & $0.214 \pm 0.009$ & $0.206 \pm 0.019$ & $0.210 \pm 0.012$ & $0.203 \pm 0.007$ & 0.811 \\
\hline
\end{tabular}

Notes: Values shown as mean $\pm \mathrm{SD} ; \mathrm{C}=$ control group; $\mathrm{E} 1, \mathrm{E} 2, \mathrm{E} 3=$ experimental groups

Table 2 MDA values in chicken thigh meat

\begin{tabular}{|c|c|c|c|c|c|c|c|}
\hline Parameter & Day & Sex & C & E1 & E2 & $\mathbf{E 3}$ & p-value \\
\hline \multirow{6}{*}{ MDA } & \multirow{2}{*}{ Day 1} & Male & $0.055 \pm 0.016$ & $0.075 \pm 0.012$ & $0.062 \pm 0.005$ & $0.083 \pm 0.011$ & 0.147 \\
\hline & & Female & $0.060 \pm 0.023$ & $0.048 \pm 0.012$ & $0.077 \pm 0.033$ & $0.073 \pm 0.021$ & 0.617 \\
\hline & \multirow{2}{*}{ Day 3} & Male & $0.189 \pm 0.023$ & $0.185 \pm 0.020$ & $0.234 \pm 0.028$ & $0.174 \pm 0.015$ & 0.103 \\
\hline & & Female & $0.198 \pm 0.011$ & $0.203 \pm 0.022$ & $0.206 \pm 0.023$ & $0.204 \pm 0.004$ & 0.978 \\
\hline & \multirow{2}{*}{ Day 5} & Male & $0.230 \pm 0.020$ & $0.226 \pm 0.007$ & $0.236 \pm 0.012$ & $0.228 \pm 0.019$ & 0.923 \\
\hline & & Female & $0.247 \pm 0.042$ & $0.246 \pm 0.014$ & $0.269 \pm 0.023$ & $0.231 \pm 0.007$ & 0.530 \\
\hline
\end{tabular}

Notes: Values shown as mean $\pm \mathrm{SD}$; C = control group; E1, E2, E3 = experimental groups

In fact, chicken breast meat contains less fat than meat from thighs, and female chicken has more fat tissue than male roosters. Both of these facts were also proven in our study by the highest volumes of MDA in female chicken thigh meat. On the first day levels of malondialdehyde in all samples was fairly even in all studied group as well as in breast compared to thigs. During the storage period, however, a visible increase of created MDA had occurred in thigh meat, especially in female individuals.

Results of the study of Brenes et al. (2008) proves that dietary grape pomace concentrate at 30 and $60 \mathrm{~g} \cdot \mathrm{kg}^{-1}$ and vitamin E can delay lipid oxidation at $1 \mathrm{st}$, 4th, and 7th day in breast meat. Similarly, Goñi et al. (2007) reported that dietary GP supplementation at the level of 15 and $30 \mathrm{~g} \cdot \mathrm{kg}^{-1}$ was effective in delaying lipid oxidation compared with $200 \mathrm{mg}$. $\mathrm{kg}^{-1} \alpha$-tocopheryl acetate diet in the breast (4th and 7 th day of storage) and thigh meat (7th day of storage). The greater efficiency in preventing lipid peroxidation in breast meat compared with thigh meat by dietary grape pomace could be justified by the greater susceptibility of thigh meat to oxidation attributed to the higher absolute content of polyunsaturated fatty acids and a large number of prooxidative agents originating 
from myoglobin and other Fe-containing proteins in thigh muscle tissues compared with breast muscle tissues.

The protective effect of dietary grape pomace against lipid oxidation however was not proven in our study. Levels of malonaldehyde measured in samples of all experimental groups and the control group were very similar. When compared, not a single juxtaposition resulted in statistically significant changes at $\alpha$ set to 0,05 . On the other hand, we did not observe any negative effects as well.

Also, studies Brenes et al. (2008), Haščík et al. (2020), states that the inclusion of red grape pomace up to $60 \mathrm{~g} \cdot \mathrm{kg}^{-1}$ did not impair the performance, digestive organ sizes, and protein digestibility.

\section{CONCLUSION}

Our study focused on oxidation stability could not confirm an improvement of groups fed with the addition of red grape pomace compared to the control group However, no negative effects were observed. Therefore, the addition of grape pomace to diet of chicken still may be an interesting option for utilization of hard to dispose agriculture waste. Further research in this direction is however strongly recommended. For the future references, quantity of pomace can be altered, or white grape pomace can be utilized.

Acknowledgments: This work was financially supported by the Slovak Research and Development Agency under contract no. APVV-18-0312 and grant KEGA 025SPU-4/2019.

\section{REFERENCES}

Aditya, S., Ohh, S.J., Ahammed, M. \& Lohakare J. (2018). Supplementation of grape pomace (Vitis vinifera) in broiler diets and its effect on growth performance, apparent total tract digestibility of nutrients, blood profile, and meat quality, 4(2), 210-214. https://doi.org/10.1016/j.aninu.2018.01.004

Allard, J., Kurian, R., Aghdassi, E., Muggli, R. \& Royall, D. (1997). Lipid peroxidation during $n-3$ fatty acid and vitamin E supplementation in humans. Lipids, 32, 535-541

Bourre J.M. (2005). Where to find omega-3-fatty acids and how feeding animals with diet enriched in omega-3-fatty acids to increase nutritional value derived products for human: What is actually useful? Journal of Nutrition Health and Aging, 9, 232-242

Brenes, A., Viveros, A., Goñi, I., Centeno, C., Sáyago-Ayerdy, S. G., Arija, I., \& Saura-Calixto, F. (2008). Effect of Grape Pomace Concentrate and Vitamin E on Digestibility of Polyphenols and Antioxidant Activity in Chickens. Poultry Science, 87(2), 307-316. https://doi.org/10.3382/ps.2007-00297

Ebrahimzadeh, S.K., Navidshad, B., Farhoomand, P. \& Mirzaei Aghjehgheshlagh, F. (2018). Effects of grape pomace and vitamin E on performance, antioxidant status, immune response, gut morphology and histopathological responses in broiler chickens. S. Afr. J. Anim. Sci. 48, 324 336. https://doi.org/10.4314/sajas.v48i2.13

Enberg R.M., Lauridsen, C., Jensen, S.K. \& Jakobsen K. (1996). Inclusion of oxidised vegetable oil in broiler diets. Influence on nutrient balance and on the antioxidative status of broilers. Poult. Science 75, 1003-1011.

Goñi, I., Brenes, A., Centeno, C., Viveros, A., Saura-Calixto, F., Rebolé, A. Arija, I. \& Estevez, R. (2007). Effect of Dietary Grape Pomace and Vitamin E on Growth Performance, Nutrient Digestibility, and Susceptibility to Meat Lipid Oxidation in Chickens. Poultry Science, 86(3), 508-516. https://doi.org/10.1093/ps/86.3.508

Gómez-Plaza, E., Miñano, A., \& López-Roca, J. M. (2006). Comparison of chromatic properties, stability and antioxidant capacity of anthocyanin-based aqueous extracts from grape pomace obtained from different vinification $\begin{array}{llll}\text { methods. } & \text { Food } & \text { Chemistry, } & \text { 97(1), }\end{array}$ https://doi.org/10.1016/j.foodchem.2005.03.025

González-Paramás, A. M., Esteban-Ruano, S., Santos-Buelga, C., de PascualTeresa, S., \& Rivas-Gonzalo, J. C. (2004). Flavanol Content and Antioxidant Activity in Winery Byproducts. Journal of Agricultural and Food Chemistry, 52(2), 234-238. https://doi.org/10.1021/jf0348727

Haščík, P., Čech, M., Čuboň, J., Bobko, M., Arpášová, H., Pavelková, A. Kačániová, M., Tkáčová J. \& Čeryová, N. (2020). Effect of grape pomace supplementation on meat performance of broiler chicken Ross 308. J Microbiol Biotech Food Sci, 10(1), 140-144 https://doi.org/10.15414/jmbfs.2020.10.1.140144

Hygreeva, D., Pandey, M. C., \& Radhakrishna, K. (2014). Potential applications of plant based derivatives as fat replacers, antioxidants and antimicrobials in fresh and processed meat products. Meat Science, 98(1), 47-57. https://doi.org/10.1016/j.meatsci.2014.04.006

Chamorro, S., Viveros, A., Rebolé, A., Rica, B. D., Arija, I., \& Brenes, A. (2015). Influence of dietary enzyme addition on polyphenol utilization and meat lipid oxidation of chicks fed grape pomace. Food Research International, 73, 197-203. https://doi.org/10.1016/j.foodres.2014.11.054

Lima, D. M., Rangel, A., Urbano, S., Mitzi, G. \& Moreno, G.M. (2013). Lipid oxidation and lamb meat quality. Acta Veterinaria Brasilica, 7(1), 14-28 https://doi.org/10.21708/avb.2013.7.1.3119
McCalluma, J.L., Yang, R., Young, J.C., Strommer, J.N. \& Tsao, R. (2007). Improved high performance liquid chromatographic separation of anthocyanin compounds from grapes using a novel mixed-mode ion-exchange reversed-phase column. Journal of Chromatography A, 1148(1), 38-45 https://doi.org/10.1016/i.chroma.2007.02.088

Min, B. \& Ahn, U. (2005). Mechanism of lipid peroxidation in meat and meat products - a review. Food Science and Biotechnology, 14(1), 152-163.

Mitsumoto, M., O’Grady, M. N., Kerry, J. P., \& Joe Buckley, D. (2005) Addition of tea catechins and vitamin $\mathrm{C}$ on sensory evaluation, colour and lipid stability during chilled storage in cooked or raw beef and chicken patties. Meat Science, 69(4), 773-779. https://doi.org/10.1016/j.meatsci.2004.11.010

Papuc, C., Goran, G. V., Predescu, C. N., Nicorescu, V., \& Stefan, G. (2017)

Plant Polyphenols as Antioxidant and Antibacterial Agents for Shelf-Life Extension of Meat and Meat Products: Classification, Structures, Sources, and Action Mechanisms. Comprehensive Reviews in Food Science and Food Safety, 16(6), 1243-1268. https://doi.org/10.1111/1541-4337.12298

Xia, E., Deng, G., Guo, Y. \& Li, H. (2010). Biological activities of polyphenols from grapes. International Journal of Molecular Science, 11(2), 622-646. https://doi.org/10.3390/ijms11020622 